\title{
WEB BASED GROUP DECISION MAKING IN HUMAN RESOURCES MANAGEMENT
}

\author{
Rokou Elena* \\ National Technical University of Athens \\ Athens, Greece \\ E-mail: erokou@mail.ntua.gr \\ Voulgaridou Dimitra \\ University of the Aegean \\ Chios, Greece \\ E-mail: dvoulg@central.ntua.gr \\ Kirytopoulos Konstantinos \\ National Technical University of Athens \\ Athens, Greece \\ E-mail: kkir@mail.ntua.gr
}

\begin{abstract}
Although every problem has multiple solutions, many restrictions and various ways to be addressed, there are also many techniques, methods and approaches proposed by scholars and practitioners that can be implemented to help increase our decision making effectiveness. The Forum will address this issue by engaging participants to reach a group decision using a proprietary web based platform that implements the Group Analytic Network Process (GANP), named WEB ANP SOLVER that is open for academic use. An illustrative case concerning the selection of the best candidate for a job position as a teaching associate based on given profiles and preselected criteria will be used during the Forum. The results of this game will provide significant insights for the group decision making process, explore the proposed techniques and bring out the advantages and disadvantages reported in literature.
\end{abstract}

Keywords: ANP, MCDA, Software tool, WEB ANP Solver, Group Decision Making

\section{Introduction}

Every key person in any organization faces situations on a daily basis where a decision should be made. Simple decisions can be and usually are, made individually. However, there are more complex decisions that involve big amounts of information, different fields of expertise and whose consequences can be of paramount importance for the organization. In these cases it is preferred to have group decisions, as it is commonly believed and empirically proven (Bonner, 2004) that a group of people working together solve problems better than each person working alone.

Every group decision making process can be roughly split in two phases, the first concerns the problem modeling while the second one is about finding out which is the preferred solution among several alternatives with respect to a set of criteria. The present study focuses on the second phase.

The Forum will address this issue by engaging participants to reach a group decision using ANP, a multicriteria decision analysis (MCDA) technique (Saaty, 1996). For this purpose, a

\footnotetext{
${ }^{*}$ Corresponding author
} 
proprietary web based platform that implements the Group Analytic Network Process (GANP), named WEB ANP SOLVER ${ }^{1}$ will be used. This software tool will provide the means for anonymously setting preferences among the criteria and the alternatives. Then, the entered judgments will be reviewed and in case of major inconsistencies, the decision makers will be asked to reevaluate their position, till an accepted level of consistency is reached. At that point, the given judgments will be aggregated and the group preferences will be calculated by the system. This way, the final results will be generated.

As all participants should be equally familiar, the illustrative case that will be used during the Forum concerns the selection of the best candidate for a job position as a teaching associate. The problem's model and thus the available alternatives and selection criteria will be given. The results of this game will provide significant insights for the group decision making process dynamics.

The rest of this paper is organized as follows: in Section 2 a brief review of group decision making, group decision support systems (GDSS) and group ANP is presented. In Section 3 the proposed Forum topic and implementation process are described. The last Section of the paper consists of general conclusions and expected learning outcomes.

\section{Theoretical Background}

\subsection{Group Decision Making}

The advantages of group's decisions over individual's (Basak and Saaty, Saunders and Miranda, 1998, Bonner et al., 2002, Bonner, 2004, Lago et al., 2007, Saaty and Shang, 2007, Saaty and Vargas, 2007, Alonso et al., 2010, Boroushaki and Malczewski, 2010) have been widely studied in literature. Group decision making makes the most of the combined individual abilities, knowledge and expertise of the group members. It leads to greater group commitment to the results of the decision making process since they share the responsibility. When deciding as a group, biased opinions and restricted perspectives cannot easily prevail. Being in a group also tends to motivate and inspire group members by enhancing their level of contribution.

On the other hand, there are several potential disadvantages of group decision making. For example, sometimes group members feel pressure to conform to what seems to be the dominant view in the group, known as groupthink. Another disadvantage of group decision making is group polarization that is the tendency of a group to converge on extreme solutions to a problem. An example of polarization is the so-called "risky shift" phenomenon that occurs when the final group decision is riskier than any of the group members would have made individually. This phenomenon is caused by the reduced feeling of accountability and responsibility of the group decision against the individual decision. Another drawback of group decision making is that the status of the group member that proposes an alternative or idea influences the reactions and acceptability level of the idea itself. Especially, when a consensus approach is used, there is a danger that the decision may represent a false consensus caused by group members that appear to accept a proposed solution or alternative but actually have objections that they choose not to share with the other members of the group. Furthermore, decision making is more time consuming and costly than the process of individual decision making since there are many opinions to be considered and valued.

In order to have an efficient and effective decision making process, it should be properly structured. There are many methods that can be used for this purpose. Some of the more commonly used group decision making methods are brainstorming, dialectical inquiry, nominal group technique, and the Delphi technique. Brainstorming is a relatively unstructured process where group members verbally suggest ideas or alternative solutions but doesn't

${ }^{1}$ Software tool available at: http://kkir.simor.ntua.gr/Rokou/ANPWEB/default.aspx 
provide a specific process for evaluating these alternatives. Its major drawback is the fear of the judgment of others that leads in non-expressed ideas. Meanwhile, dialectical inquiry is based on the division of the group in two opposing sides that are asked to debate the advantages and disadvantages of the proposed solutions. A more structured approach is provided by the nominal group technique where group members are asked to separately think and provide written lists of ideas or alternatives solutions to a problem. During the second phase of the process the ideas are publicly recorded and rated or ranked in order of preference. However, in cases that group members are situated in different physical locations and/or experts' opinion is essential the Delphi method is used. The process is structured in rounds. During each round the group members propose ideas and/or alternative solutions. After each round, an anonymous summary from the previous round containing the ideas along with the reasoning that supports each idea is generated. Then group members are encouraged to revise their earlier answers in light of the replies of the other members. After an undefined number of rounds, consensus is reached.

Summarizing, group decision making can be a valuable tool for decision makers when a carefully structured approach is followed. The method used for group decision making should be based on the needs and characteristics of the specific group and problem that is being solved and should provide mechanisms for avoiding common pitfalls, like groupthink and group polarization.

To support the above process Group Decision Support Systems (GDSSs) are used. A GDSS is an interactive computer-based system that facilitates the solution of problems by a group of decision makers which work together as a team (Kraemer and King, 1988). This can be achieved by removing communication barriers, providing procedures for structuring decision analysis and conducting the pattern, timing and content of the discussion in a systematic manner (DeSanctis and Gallupe, 1987). Furthermore, studies have shown that a GDSS may establish a level of anonymity and loose internal structure in group decision that can favourably affect and enhance contribution of each group member no matter if the group is multicultural or homogeneous (Daily and Steiner, 1998). Another positive about using GDSS is that it facilitates information access during all step of the decision process (Saunders and Miranda, 1998).

During the herein described Forum, attendees will be given a specific human resources decision problem and they will be step by step assisted in using a Multi Criteria Decision Support (MCDA) technique, namely Group ANP, to make a group decision. The employed method is briefly described in the following section.

\subsection{Group ANP}

The Analytic Network Process (ANP) is a MCDA approach developed by Thomas Saaty in 1996 (Saaty, 1996). It is a theory of relative measurement on absolute scales of both tangible and intangible criteria, called elements and their classification in groups, clusters, based on their commonalities. Input data comprise of the judgments of expert decision makers and qualitative/quantitative criteria. The model components are clusters and elements that have interdependent relationships and incorporate feedback. Thus, ANP achieves an accurate representation of real life problems especially in cases where there is a high degree of risk and uncertainty (Saaty, 2010). Technically, the ANP method provides an algorithm for the homogenization of judgments used to compute the relative priorities of the model components. This way relative importance among criteria and clusters that influence the decision is presented (Kirytopoulos et al., 2008).

A framework for group decision using the ANP method was initially proposed by Saaty and Shang (2007) in order to provide a method that brings about consensus and at the same time prevents one person from dominating a meeting. In this section the algorithm of group ANP is briefly presented: 
$\mathbf{1}^{\text {st }}$ step: Development of an ANP model that describes the problem to be solved. This step includes the analysis and modelling of the problem, the identification of alternatives and criteria and their classification in clusters.

$\mathbf{2}^{\text {nd }}$ step: The paths of influence among the elements should be described. This step leads to the creation of a network containing all the decision elements and their inner (within the same cluster) and outer relationships (among elements of different clusters).

$\mathbf{3}^{\text {rd }}$ step: This step is slightly different from the corresponding in standard ANP. In group ANP we have a group of decision makers that each one gives his/her judgments independently, instead of having just one decision maker (Kirytopoulos et al., 2011).

$4^{\text {th }}$ step: Taking as granted that each decision maker's individual set of judgments is within an acceptable level of consistency, all judgments are combined using an aggregation function to generate the Supermatrix and the Cluster matrix.

$5^{\text {th }}$ step: The Supermatrix is weighted by the Cluster matrix and thus transformed to the column stochastic Weighted Supermatrix.

$6^{\text {th }}$ step: The Weighted Supermatrix is limited by raising it to a sufficiently large power until it converges into a stable limit matrix. In the end, the weights of criteria and alternatives will lead to the final priorities.

\section{Forum description and implementation}

\subsection{General Description of the Decision Problem}

The decision problem concerns the selection of the best candidate for a job position as a teaching associate based on given profiles and preselected criteria. It is a simplified version of a classical human resources decision problem. The specific decision environment is considered appropriate as it falls within the knowledge and experience of all attendees, while some of them, hopefully, might be able to provide further insights, in case they have themselves participated in similar processes.

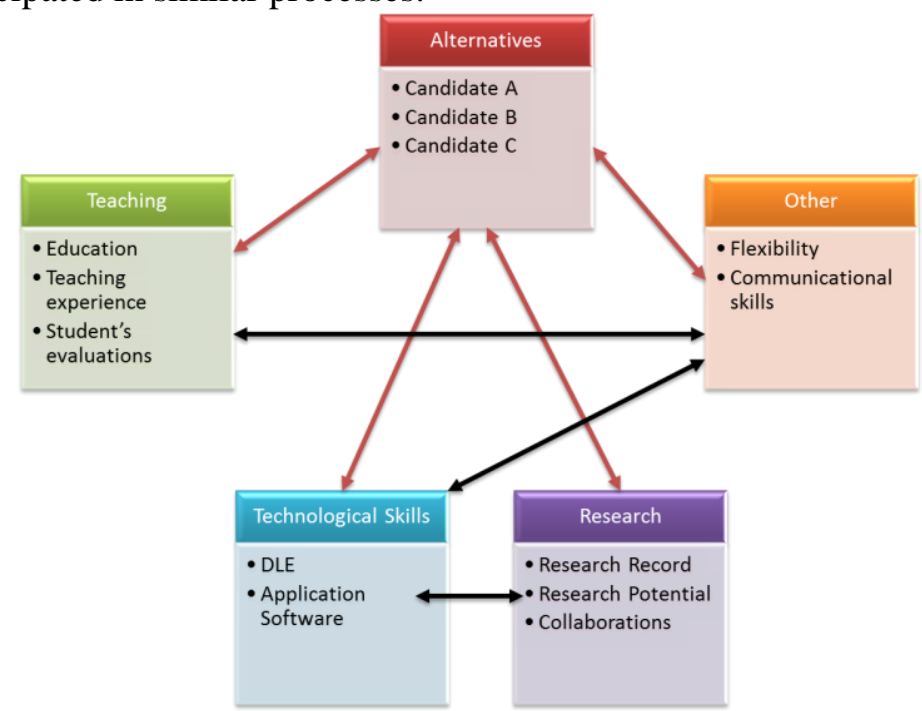

Figure 1 Faculty selection model

Here the aim is the group decision process and not the problem itself. This is the reason that criteria and alternatives will not be a result of group discussion but provided by the 
presenters. Following the criteria used to form the ANP decision model and the way that are grouped in clusters are analyzed. Teaching cluster consists of the criteria related to the candidate's education, teaching experience in tertiary level of education and the student's evaluations of past courses. Research cluster contains criteria related to the research experience and skill of the candidate. Technological skills cluster is used to group together criteria related to the ability of the candidate to use software applications related to his thers discipline and provide distance learning courses. Finally, the flexibility of the candidate and his her communicational skills are grouped under the cluster "Other". The proposed model is shown in Figure 1.

\subsection{Group decision making processes}

The group decision making process that will be followed is depicted in Figure 2 and analysed hereafter.

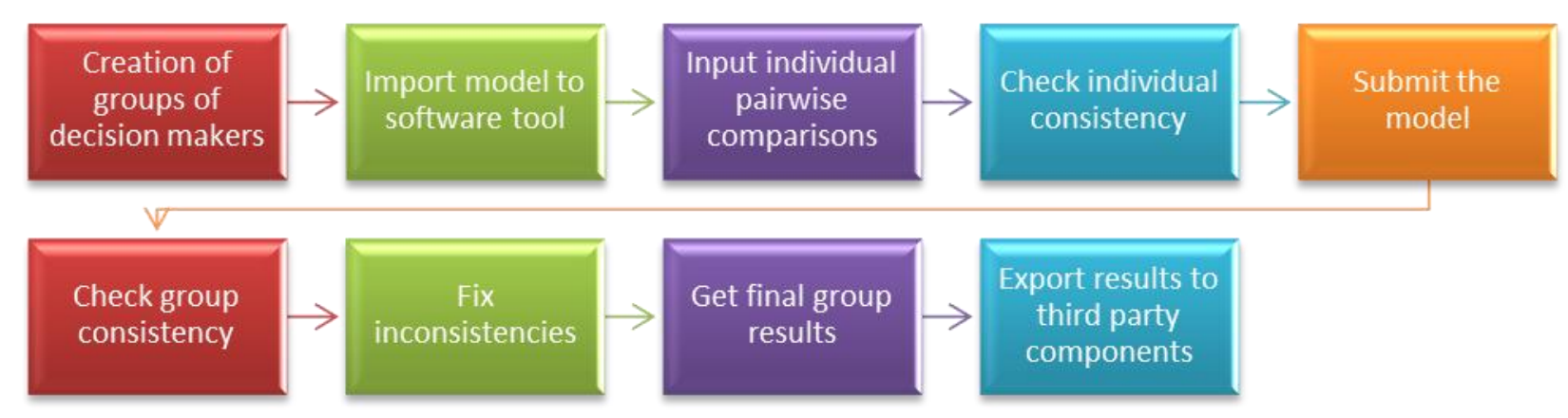

Figure 2 Group decision making process

Initially, according to the number of attendees groups of decision makers will be formed and a member of each group will get the role of the facilitator. Those that have previously taken part in a similar decision will join the same group and will be considered as 'experts'. Then a model previously created in another software tool, for example Super Decisions (http://www.superdecisions.com/) will be imported to WEB ANP SOLVER and each group's facilitator will create his/her session and ask his/her group members to join it.

Following, each decision maker will input his/her judgments, check for inconsistencies in the inserted values and accordingly adjust their judgments. The first part of the process is completed when all group members have submitted their judgments.

During the second phase of the process, the facilitator will check for group inconsistencies and if needed ask for corrective actions. Finally, the facilitator closes the session by requesting the computation of the final group results and makes those results available to all group members for further analysis or export to third party components, like Microsoft Excel spreadsheets or Super Decisions.

\section{Conclusion-Learning points}

A final conclusion will be derived and the main learning points concerning both the group decision process and the method used will be clarified. Among completion of the session the attendees will have learned tips and tricks for group decision making and acquired basic understanding for using the ANP method and the WEB ANP SOLVER tool in the real world decisions. 


\section{REFERENCES}

Alonso, S., Herrera-Viedma, E., Chiclana, F. \& Herrera, F. 2010. A web based consensus support system for group decision making problems and incomplete preferences. Information Sciences, 180(23), 4477-4495.

Basak, I. \& Saaty, T. Group decision making using the analytic hierarchy process. Mathematical and Computer Modelling, 17(4-5), 101-109.

Bonner, B. L. 2004. Expertise in Group Problem Solving: Recognition, Social Combination, and Performance. Group Dynamics, 8(4), 277-290.

Bonner, B. L., Baumann, M. R. \& Dalal, R. S. 2002. The effects of member expertise on group decision-making and performance. Organizational Behavior and Human Decision Processes, 88(2), 719-736

Boroushaki, S. \& Malczewski, J. 2010. Measuring consensus for collaborative decisionmaking: A GIS-based approach. Computers, Environment and Urban Systems, 34(4), 322332.

Daily, B. F. \& Steiner, R. L. 1998. The influence of group decision support systems on contribution and commitment levels in multicultural and culturally homogeneous decisionmaking groups. Computers in Human Behavior, 14(1), 147-162.

Desanctis, G. \& Gallupe, R. B. 1987. A foundation for the study of group decision support systems. Manage Sci, 33(5), 589-609.

Kirytopoulos, K., Leopoulos, V. \& Voulgaridou, D. 2008. Supplier selection in pharmaceutical industry: An analytic network process approach. Benchmarking, 15(4), 494516.

Kirytopoulos, K., Voulgaridou, D. \& Rokou, E. 2011. 'ANP SOLVER, an alternative tool for implementing the ANP method'. International Journal of Applied Decision Sciences (IJADS). Kraemer, K. L. \& King, J. L. 1988. Computer-based systems for cooperative work and group decision making. ACM Comput. Surv., 20(2), 115-146.

Lago, P. P., Beruvides, M. G., Jian, J.-Y., Canto, A. M., Sandoval, A. \& Taraban, R. 2007. Structuring group decision making in a web-based environment by using the nominal group technique. Computers \& Industrial Engineering, 52(2), 277-295.

Saaty, T. 2010. Principia Mathematica Decernendi: Mathematical Principles of Decision Making, Pittsburgh, RWS Publications.

Saaty, T. L. 1996. Decision making with dependence and feedback: the analytic network process, Pittsburgh, RWS Publications.

Saaty, T. L. \& Shang, J. S. 2007. Group decision-making: Head-count versus intensity of preference. Socio-Economic Planning Sciences, 41(1), 22-37.

Saaty, T. L. \& Vargas, L. G. 2007. Dispersion of group judgments. Mathematical and Computer Modelling, 46(7-8), 918-925.

Saunders, C. \& Miranda, S. 1998. Information acquisition in group decision making. Information \& Management, 34(2), 55-74. 